\title{
HUBUNGAN KONDISI SPIRITUAL DENGAN KEMAMPUAN RESILIENSI KLIEN BIDAN
}

\author{
Maya Sukmayati ${ }^{1}$, Evi Kusumahati ${ }^{2}$, Santy Sanusi ${ }^{3}$ \\ ${ }^{1,2)}$ Program Studi S1 Kebidanan Fakultas Ilmu Kesehatan \\ Universitas 'Aisyiyah Bandung \\ 3) Program Studi Profesi Ners Fakultas Ilmu Kesehatan \\ Universitas 'Aisyiyah Bandung \\ mayasukmayati@gmail.com
}

\begin{abstract}
ABSTRAK
Sehat sebagai sebuah kondisi terintegrasinya kesejahteraan fisik, mental, sosial maupun spiritual adalah merupakan amanah undang-undang yang belum sepenuhnya dapat dinikmati oleh masyarakat Indonesia secara umum. Mayoritas pelayanan kesehatan, khususnya kebidanan yang diberikan petugas kesehatan masih terfokus pada kebutuhan fisik. Padahal, beberapa penelitian memperlihatkan adanya korelasi bermakna antara kesejahteraan spiritual dengan keagamaan dan kondisi fisik manusia. Penelitian ini menggunakan metode kuantitatif korelasi dengan sampel 58 orang klien bidan dalam periode kehamilan, persalinan dan nifas yang memenuhi kriteria inklusi. Hubungan variabel bebas dengan variabel terikat diolah menggunakan teknik product moment. Hasil uji statistik menunjukkan korelasi kondisi spiritual dengan resiliensi psikologi klien memiliki nilai sig (2-tailed) 0,000, menunjukan adanya hubungan yang bermakna antara dua variabel. Kondisi spiritual yang baik berhubungan dengan kemampuan resiliensi klien yang dapat meningkatkan adaptasi klien dalam menghadapi ketidaknyamanan di masa kehamilan, persalinan dan nifas sehingga proses - proses tersebut dapat lebih mudah dilalui.
\end{abstract}

Kata kunci : asuhan kebidanan, asuhan spiritual, klien bidan, resiliensi

\begin{abstract}
Health as an integrated condition of physical, mental, social, and spiritual well-being is a mandate of the constitution that the Indonesian people have not thoroughly enjoyed. Most health services, especially midwifery care by health workers, are still focused on physical needs. Several studies show a significant correlation between spiritual well-being with religion and human physical condition. This study used a quantitative correlation method with a sample of 58 midwife clients in the period of pregnancy, childbirth, and postpartum who met the inclusion criteria. The relationship between the independent variable and the dependent variable was processed using the product-moment technique. The result of the statistic test with the value of sig (2-tailed) is 0.000 have shown that there was a significant correlation between the two variables. Good spiritual condition is related to the client's resilience ability that can improve the client's adaptation in the face of discomfort in pregnancy, childbirth, and postpartum so that the processes can quickly pass.
\end{abstract}

Keywords: midwifery care, spiritual care, midwives clients, resilience 


\section{PENDAHULUAN}

Penelitian ini bertujuan untuk melihat apakah ada hubungan antara kondisi spiritual dengan kemampuan resiliensi klien-klien bidan dalam menghadapi ketidaknyamanan selama periode kehamilan, persalinan dan nifas. Asuhan kebidanan sebagai bagian integral dari pelayanan kesehatan memberikan kontribusi terhadap pemenuhan kualitas kesehatan holistik masyarakat.

Kesehatan holistik adalah suatu kondisi sejahtera yang meliputi dimensi fisik, mental, spiritual dan sosial sebagaimana tertuang dalam Undang Undang Kesehatan Nomor 36 Tahun 2009 (Kartini, 2021).

\section{World Health Organisation (WHO)} sampai saat ini masih belum menerima dimensi spiritual sebagai salah satu dimensi sehat sebagaimana direkomendasikan dalam World Health Assembly tahun 1984. Hal tersebut dikarenakan beberapa pendapat menyatakan dimensi spiritual tidak berpengaruh terhadap kesehatan, tetapi lebih kepada kebahagiaan (Chirico, 2016). Sebaliknya, penelitianpenelitian terdahulu, menunjukkan adanya korelasi antara kondisi spiritual dengan kesehatan fisik (MahdiNejad dkk., 2020). Beberapa peneliti memisahkan antara relijiusitas dan spiritualitas, tetapi semua sepakat ada hubungan antara relijius dan spiritualitas (Astrachan dkk., 2020). Adapun relijiusitas berhubungan dengan perilaku yang mendukung kesehatan (Natalie A dkk., 2017)

Masyarakat dan budaya Sunda memiliki hubungan yang erat dengan agama Islam (Suyatman, 2019).

Sebagaimana karakteristik masyarakat Indonesia secara umum dan masyarakat Sunda, masyarakat Kabupaten Bandung juga memiliki keyakinan beragama yang baik tetapi pengamalan nilai-nilai keagamaan masih rendah (Jaenudin \& Tahrir, 2019)

Karakteristiksikapkeagamaan danbudaya masyarakat Sunda sangatmembuka peluang untuk mendapatkan asuhan spiritual dalam pelayanan kesehatan, khususnya pelayanan kebidanan. Di sisi lain, Bidan sebagai bagian integral dari petugas pelayanan kesehatan bertanggung jawab memberikan pelayanan kesehatan holistik secara langsung kepada klien, khususnya kesehatan ibu dan anak. Sikap keagamaan juga berhubungan dengan perilaku-perilaku yang mendukung kesehatan pada ibu-ibu hamil (Natalie A dkk., 2017). Fakta di lapangan maupun berdasarkan evaluasi buku catatan pelayanan kebidanan, fokus terbesar dari asuhan kebidanan masih terbatas pada pemenuhan kebutuhan fisik, mental dan sosial (Kemenkes RI, 2016). Sedangkan standar kompetensi bidan memberi peluang yang sangat terbuka serta dukungan bagi bidan untuk berinovasi dalam pemberian asuhan normal (Sefrina Werni dkk., 2020)nilai rata-rata uji kompetensi DIII kebidanan hanya 41,08. Peserta uji kompetensi yang belum lulus sebanyak $46,5 \%$. Hasil yang masih jauh dari harapan juga ditunjukkan dari rerata try out uji kompetensi tenaga kesehatan tahun 2012 hingga tahun 2015 yang cenderung menurun. Kajian ini bertujuan untuk mendapatkan informasi identifikasi kompetensi bidan berdasarkan Kepmenkes 369/ MENKES/SK/III/2007 tentang standar profesi bidan pada hasil Risdiknakes tahun 2017. Kajian dilakukan menggunakan observasi, wawancara mendalam dan literatur review. Informan adalah bidan di puskesmas dan pakar kebidanan. Hasil kajian menunjukkan bahwa kompetensi bidan di fasilitas pelayanan kesehatan masih belum sesuai standar. Beberapa faktor dalam penyelenggaraan pendidikan kebidanan turut membentuk kompetensi bidan yang dihasilkan. Proses rekrutmen calon peserta didik, kualitas dosen, dan proses penyelenggaraan pendidikan kebidanan secara keseluruhan merupakan komponen yang harus menjadi fokus untuk menghasilkan bidan yang sesuai dengan standar 
kompetensi seperti tercantum dalam Kepmenkes Nomor 369/MENKES/SK/III/2007.Kata kunci: kompetensi bidan, kajian kebidanan, pendidikan bidan, kurikulum kebidananAbstractMidwives are strategic health workers who play an important role in maternal and child health services. They are required to have well competencies to run their tasks properly. Well, competencies can be achieved if the midwife's professional education providers meet the standards. Based on the Indonesian Health Workers' Assembly (MTKI. Walaupun kondisi mayoritas klien bidan adalah normal, kadar hormon yang tidak stabil dan perubahan fisik yang dialami klien dalam masa kehamilan dan persalinan akan menimbulkan ketidaknyamanan yang berujung stress bahkan depresi, sehingga tetap harus disikapi (Míguez \& Vázquez, 2021).

Kegagalan klien dalam mengendalikan rasa cemas dan ketidaknyamanan selama proses kehamilan dapat mengantarkannya pada kondisi patologis yang memerlukan intervensi medis (Grigoriadis dkk., 2018). Kondisi tersebut diperberat dengan adanya pandemi Covid 19 yang berdampak juga pada kondisi sosial maupun ekonomi para klien kebidanan. Kondisi spiritual yang terabaikan dapat mengancam kesejahteraan fisik, sosial maupun spiritual, selain mengakibatkan krisis sosial (Asadzandi, 2018). Sebaliknya kesejahteraan spiritual berpengaruh terhadap peningkatan resiliensi individu di masa pandemi Covid - 19 (Roberto dkk., 2020)

Tidak banyak penelitian terkait hubungan kondisi spiritual dengan kesakitan dan ketidaknyamanan klien dalam masa kehamilan, persalinan maupun nifas. Beberapa penelitian terkait menemukan adanya hubungan antara rasa sakit dalam jangka waktu lama seperti pada kasus klien perawatan paliatif dan pasien cedera punggung dengan tingkat spiritual pasien. Selain itu kesejahteraan spiritual juga berhubungan negatif dengan kejadian depresi dan berhubungan positif dengan resiliensi maupun self efikasi terhadap rasa sakit (Siddall dkk., 2017)New South Wales, Australia.InMethods: Questionnaires evaluating pain, psychological and spiritual well-being were administered to a group of people with a spinal cord injury $(\mathrm{n}=$ 53. Kondisi spiritual juga berhubungan dengan stress dan rasa cemas (Musa dkk., 2017). Sementara terdapat perbedaan karakteristik rasa sakit dan ketidaknyamanan pada para ibu dalam masa kehamilan, persalinan dan nifas, dimana rasa sakit dan tidak nyaman bersifat temporer dan alami.

\section{METODOLOGI}

Penelitian ini menggunakan metode kuantitatif korelasi dengan populasi target dalam penelitian ini adalah seluruh ibu hamil, bersalin dan nifas yang menjadi klien bidan di wilayah kerja Kabupaten Bandung dalam kurun waktu tertentu. Adapun populasi terjangkaunya adalah seluruh klien bidan yang hadir mengisi kuesioner dan memenuhi kriteria untuk dilakukan pengambilan data. Sampel penelitian ditentukan secara purposive, yaitu seluruh sampel yang memenuhi kriteria dalam kurun waktu tertentu diambil dengan teknik non probability sample (Sekar Prihanti, 2016). Terdapat 58 responden yang memenuhi kriterian inklusi, yaitu klien bidan yang berdomisili di Bandung Raya dan mengalami kasus kehamilan, persalinan maupun nifas normal untuk dilibatkan dalam penelitian.

Kondisi spiritual kelompok responden dinilai menggunakan instrumen modifikasi Spiritual Well-Being Scale (SWBS) untuk menentukan kondisi kesejahteraan spiritual responden. Modifikasi (CDRISC 25) digunakan untuk mengukur resiliensi psikologi klien.

Uji validitas dilakukan pada 30 responden berasal dari Bandung Barat dengan menggunakan pearson product moment dan uji reliabilitas dengan menggunakan alpha cronbach. Terdapat 
3 butir soal yang tidak valid dengan nilai $r$ hitung $\leq \mathrm{r}$ tabel dan nilai alpha $<0.50$, yaitu no $1,5,8$ sehingga jumlah butir soal yang akan diujikan menjadi sebanyak 23 soal.

Selanjutnya dilakukan uji normalitas dengan Kolmogorov-Smirnov ${ }^{\mathrm{a}}$ dan uji linieritas dengan Anova, didapat hasil variabel-variabel yang hendak di uji berdistribusi normal dan hubungan kedua variabel linier. Hubungan variabel bebas dengan variabel terikat diolah menggunakan teknik Pearson Product Moment dengan hasil uji korelasi menunjukkan ada hubungan antara kondisi spiritual dengan resiliensi psikologi.

HASIL

Tabel 1. Penyajian Data Deskriptif Kondisi Spiritual

\begin{tabular}{cccc}
\hline & f & \% & $\begin{array}{c}\text { Persentase } \\
\text { Kumulatif }\end{array}$ \\
\hline Rendah & 1 & 1,7 & 1,7 \\
Sedang & 2 & 3,4 & 5,2 \\
\hline
\end{tabular}

\begin{tabular}{cccc}
\hline & f & \% & $\begin{array}{c}\text { Persentase } \\
\text { Kumulatif }\end{array}$ \\
\hline Tinggi & 55 & 94,8 & 100 \\
\hline Total & $\mathbf{5 8}$ & $\mathbf{1 0 0}$ & \\
\hline
\end{tabular}

Berdasarkan hasil tabulasi data deskriptif, terdapat 55 orang responden (94\%) dengan kategori tingkat spiritual yang tinggi dan 1 orang responden $(1,7 \%)$ masuk ke dalam kategori rendah.

Tabel 2. Penyajian Data Deskriptif Resiliensi Psikologi

\begin{tabular}{lccc}
\hline & f & $\mathbf{\%}$ & $\begin{array}{c}\text { Persentase } \\
\text { Kumulatif }\end{array}$ \\
\hline Rendah & 5 & 8,6 & 8,6 \\
Sedang & 11 & 19,0 & 19,0 \\
Tinggi & 42 & 72,4 & 72,4 \\
\hline Total & $\mathbf{5 8}$ & $\mathbf{1 0 0}$ & $\mathbf{1 0 0}$ \\
\hline \multicolumn{4}{c}{ Berdasarkan hasil tabulasi data deskriptif, } \\
terdapat 42 orang responden (72,4\%) dengan \\
kategori tingkat resiliensi yang tinggi dan 5 orang \\
responden (8,6\%) \\
rendah.
\end{tabular}

Tabel 3. Penyajian Data hasil korelasi antara kondisi spiritual dengan Resiliensi Psikologi

\begin{tabular}{cccc}
\hline & & Spiritual & Resiliensi \\
\hline Spiritual & Pearson Correlation & 1 & $.569^{* *}$ \\
& Sig. (2-Tailed) & & .000 \\
Resiliensi & N & 58 & 58 \\
& Pearson Correlation & $.569^{* *}$ & 1 \\
& Sig. (2-Tailed) & .000 & \\
& $\mathrm{~N}$ & 58 & 58 \\
\hline
\end{tabular}

Berdasarkan hasil uji korelasi menunjukkan nilai signifikansi $<0,05$, sehingga kedua variabel ini dinyatakan memiliki hubungan yang signifikan.

\section{PEMBAHASAN}

Seorang perempuan pada masa kehamilan mengalami perubahan hormonal yang sangat cepat dengan tingkatan yang jauh lebih tinggi dibanding dengan kondisi normal. Selain kelelahan dan keluhan mual pagi hari (morning sickness), perubahan hormon terutama estrogen yang sangat cepat tersebut menyebabkan kondisi mood yang berubah (Gosmawi \& Mukherjee, 2020). Kondisi persalinan dengan adanya ketidaknyamanan akibat kontraksi seperti ini juga membuat perasaan ibu bersalin menjadi lebih sensitif. Pada ibu nifas, stress fisik 
maupun psikologi yang dialami oleh ibu lebih banyak diakibatkan karena perubahan peran dan kelelahan fisik. Beberapa ahli mengatakan bahwa individu dengan kondisi spiritual yang baik memiliki kemampuan resiliensi yang juga lebih baik saat berada dalam kondisi tertekan.

Berbagai penelitian menunjukkan bahwa ada hubungan antara satu dimensi sehat dengan dimensi lainnya. Kondisi fisik yang tidak baik berhubungan dengan kondisi spiritual, mental maupun sosial. Demikian pula sebaliknya. Penelitian lain juga menunjukkan adanya hubungan antara kondisi spiritual dengan kemampuan resiliensi psikologi. Tingkat kemampuan beradaptasi dengan stress yang lebih tinggi juga ditemukan pada mereka yang memiliki keyakinan spiritual dibandingkan dengan yang tidak (Akbari \& Hossaini, 2018; Chirico, 2016).

Pengalaman spiritual berhubungan dengan penurunan aktifitas Lobus Parietal Inferior Kiri yang berkontribusi penting pada proses persepsi dan representasi diri. Penurunan aktifitas pada kondisi ini juga terlihat di bagian otak yang terlibat dalam proses sensoris dan emosi, yaitu Thalamus Belakang dan Tengah. Bermakna, seseorang dengan tingkat spiritual yang baik cenderung memiliki respon rangsang dan emosi yang rendah. Kondisi inilah yang menyebabkan seseorang dengan tingkat spiritual yang baik cenderung mampu mengendalikan stress (Miller dkk., 2019). Spiritualitas juga memengaruhi kemampuan resiliensi seseorang karena alasan tersebut.

Berbagai penelitian menemukan bahwa terdapat hubungan antara kesejahteraan spiritual dengan kemampuan untuk melakukan meditasi keagamaan dan relaksasi. Adapun meditasi keagamaan berpengaruh terhadap peningkatan toleransi seseorang terhadap rasa sakit(Sollgruber dkk., 2018).

Tingkat spiritual tidak secara langsung berhubungan dengan penurunan rasa sakit atau ketidaknyamanan serta tingkat kesejahteraan pada ibu-ibu klien bidan dalam masa kehamilan, persalinan maupun nifas. Namun, spiritualitas diperlukan sebagai media untuk meningkatkan kemampuan koping dan resiliensi psikologi terhadap rasa sakit agar ibu-ibu tersebut dapat melalui beberapa periode reproduksi dengan keadaan sejahtera(Firth dkk., 2019). Spiritualitas juga diperlukan untuk meningkatkan perilakuperilaku yang mendukung kesehatan pada ibuibu hamil seperti kepatuhan terhadap prosedur pelayanan kebidanan serta motivasi untuk melakukan yang terbaik dalam menjalani kehamilannya sehingga proses asuhan menjadi lebih mudah, lancar dan efisien.

\section{SIMPULAN DAN SARAN}

Hasil analisis penelitian ini menunjukkan terdapat hubungan signifikan antara kondisi spiritual klien bidan dalam masa kehamilan, persalinan dan nifas dengan kemampuan resiliensi psikologi. Seseorang dengan kondisi spiritual yang sejahtera memiliki kemampuan resiliensi yang baik karena penerimaan terhadap rangsangan stress rendah. Tingkat stress yang rendah menyebabkan klien bidan memiliki toleransi yang baik terhadap rasa sakit dan ketidaknyamanan selama kehamilan, persalinan dan nifas. Perlu dilakukan perbaikan pengkajian kondisi spiritual secara lebih mendalam sebelum memberikan asuhan kebidanan baik pada ibu hamil, bersalin maupun nifas. Selain itu disarankan agar asuhan spiritual diberikan terintegrasikan pada asuhan kebidanan untuk meningkatkan resiliensi pada klien bidan.

\section{DAFTAR PUSTAKA}

Akbari, M., \& Hossaini, S., M. (2018). The Relationship of Spiritual Health with Quality of Life, Mental Health, and Burnout: The Mediating Role of 
Emotional Regulation. Iranian journal of psychiatry, 13(1), 22-31.

Asadzandi, M. (2018). Spiritual Health Consulting Model for Health Promotion in Clients. Health Spiritual Med Ethics, 5(2), 9-15.

Astrachan, J. H., Astrachan, B., C, C., \& G. (2020). Values, Spirituality and Religion: Family Business and the Roots of Sustainable Ethical Behavior. $J$ Bus Ethics, 163, 637-645.

Chirico, F. (2016). Spiritual well-being in the 21 st century. Journal of Health and Social Sciences, 1(1), 11-16. https://doi. org/10.29104/2016/sprt2

Chomaria, S., N. (2014). Five in One: The Series of Pregnancy, Melahirkan Tanpa Rasa Sakit. Elex Media Komputindo.

Firth, A. M., Cavallini, I., Sütterlin, S., \& Lugo, R. G. (2019). Mindfulness and selfefficacy in pain perception, stress and academic performance. The influence of mindfulness on cognitive processes. Psychology Research and Behavior Management, 12, 565-574. PubMed. https://doi.org/10.2147/PRBM.S206666

Gosmawi, A., \& Mukherjee, I. (2020). Pregnancy And Menstrual Cycle. Bazooka Publication.

Grigoriadis, S., Graves, L., Peer, M., Mamisashvili, L., Tomlinson, G., Vigod, S. N., Lee Dennis, C., Steiner, M., Brown, C., Amy, C., Dawson, H., Rector, N. A., Guenette, M., \& Richter, M. (2018). Maternal Anxiety During Pregnancy and the Association With Adverse Perinatal Outcomes: Systematic Review and MetaAnalysis. J Clin Psychiatry, 79(5).

Jaenudin, U., \& Tahrir, T. (2019). Studi Religiusitas, Budaya Sunda, dan Perilaku Moral pada Masyarakat Kabupaten Bandung. Jurnal Psikologi Islam
Dan Budaya, 2(1), 1-8. https://doi. org/10.15575/jpib.v2i1.3445

Kartini, F. (2021). Edukasi Holistik meningkatkan Self Efficasy Ibu Menghadapi Persalinan. Deepublish.

Kemenkes RI. (2016). Buku Kesehatan Ibu dan Anak. Kemenkes RI dan JICA.

MahdiNejad, J., H, A., \& H, S. H. (2020). A Religion and Spirituality: Mental Health Arbitrage in the Body of Mosques Architecture. Journal Religion Health, 59, 1635-1651.

Miller, L., Balodis, I. M., McClintock, C. H., Xu, J., Lacadie, C. M., Sinha, R., \& Potenza, M. N. (2019). Neural Correlates of Personalized Spiritual Experiences. Cerebral Cortex, 29(6), 2331-2338. https://doi.org/10.1093/cercor/bhy102

Musa, A., Pevalin, D., \& Khalaileh, M. (2017). Spiritual Well-Being, Depression, and Stress Among Hemodialysis Patients in Jordan. Journal of Holistic Nursing, 36, 089801011773668 . https://doi. org/10.1177/0898010117736686

Natalie A, C., Andrea D, C., \& Glenda, L. (2017). The Relationship Between Religiosity and Health-Promoting Behaviors in Pregnant Women. West $J$ Nurs Res, 39(11), 1429-1446. https://doi. org/10.1177/0193945916679623

Roberto, A., Sellon, A., Cherry, S. T., HunterJones, J., \& Winslow, H. (2020). Impact of spirituality on resilience and coping during the COVID-19 crisis: A mixedmethod approach investigating the impact on women. Health Care for Women International, 41(11-12), 1313-1334. https://doi.org/10.1080/07399332.2020.1 832097

Sefrina Werni, Rosita Rosita, Nita Prihartini, \& Mieska Despitasari. (2020). Identifikasi Kompetensi Bidan: Data Riset Pendidikan 
Tenaga Kesehatan Tahun 2017. Jurnal Penelitian dan Pengembangan Pelayanan Kesehatan, 3(3). https://doi. org/10.22435/jpppk.v3i3.2458

Sekar Prihanti, G. (2016). Pengantar Biostatistik. UMMPress.

Siddall, P. J., McIndoe, L., Austin, P., \& Wrigley, P. J. (2017). The impact of pain on spiritual well-being in people with a spinal cord injury. Spinal Cord, 55(1), 105-111. https://doi.org/10.1038/sc.2016.75

Sollgruber, A., Bornemann-Cimenti, H.,
Szilagyi, I.-S., \& Sandner-Kiesling, A. (2018). Spirituality in pain medicine: A randomized experiment of pain perception, heart rate and religious spiritual well-being by using a single session meditation methodology. PLOS ONE, 13(9), e0203336. https://doi. org/10.1371/journal.pone.0203336

Suyatman, U. (2019). Sistem Kepercayaan Dan Karakteristik Masyarakat Sunda: Memahami Kembali Islam Teh Sunda, Sunda Teh Islam. Al-Tsaqafa, 16(2). 
